BMC

Oral Health

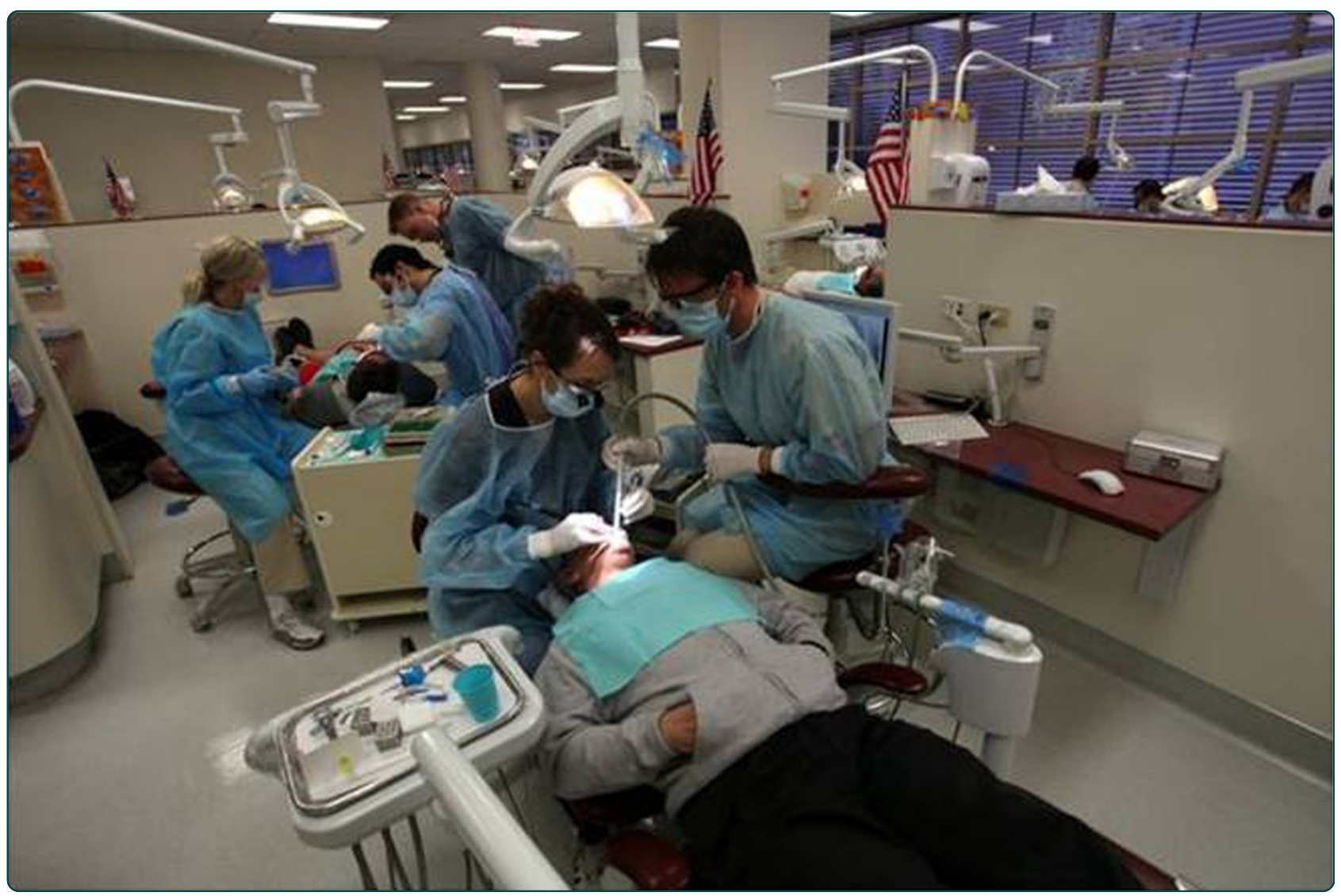

Screening and detection of human papillomavirus (HPV) high-risk strains HPV16 and HPV18 in saliva samples from subjects under 18 years old in Nevada: a pilot study

Flake et al.

C Biomed Central 


\title{
Screening and detection of human papillomavirus (HPV) high-risk strains HPV16 and HPV18 in saliva samples from subjects under 18 years old in Nevada: a pilot study
}

\author{
Colton Flake ${ }^{1}$, Jamal Arafa ${ }^{2}$, Alex Hall ${ }^{3}$, Eryn Ence ${ }^{4}$, Katherine Howard ${ }^{4}$ and Karl Kingsley ${ }^{4 *}$
}

\begin{abstract}
Background: Human papillomaviruses (HPV) are oncogenic and mainly associated with cervical cancers. Recent evidence has demonstrated HPV infection in other tissues, including oral epithelia and mucosa. Although a recent pilot study provided new information about oral HPV status in healthy adults from Nevada, no information was obtained about oral HPV prevalence among children or teenagers, therefore, the goal of this study is to provide more detailed information about oral prevalence of high-risk HPV among children and teenagers in Nevada.

Methods: This retrospective study utilized previously collected saliva samples, obtained from pediatric dental clinic patients (aged 2 - 11) and local school district teenagers (aged 12-17) for high-risk HPV screening ( $n=118)$ using qPCR for quantification and confirmation of analytical sensitivity and specificity.

Results: A small subset of saliva samples were found to harbor high-risk HPV16 $(n=2)$ and HPV18 $(n=1)$, representing a $2.5 \%$ of the total. All three were obtained from teenage males, and two of these three samples were from White participants.

Conclusions: Although this retrospective study could not provide correlations with behavioral or socioeconomic data, this project successfully screened more than one hundred saliva samples for high-risk HPV, confirming both HPV16 and HPV18 strains were present in a small subset. With increasing evidence of oral HPV infection in children, this study provides critical information of significant value to other dental, medical, oral and public health professionals who seek to further an understanding of oral health and disease risk in pediatric populations.
\end{abstract}

Keywords: Human papillomavirus, Saliva, Oral screening

\section{Background}

The human papillomaviruses (HPV) encompass a closely related family of DNA viruses, which are capable of integrating into the human genome to drive transformation of infected epithelia [1-4]. Much of the epidemiological evidence for HPV-driven carcinogenesis, as well as the biological mechanisms, have been derived from studies of cervical cancers [5-7] that isolated high-risk HPV from both adeno- and squamous cell carcinomas [6-9]. Although high-risk HPV drives the transformation and

\footnotetext{
* Correspondence: karl.kingsley@unlv.edu

${ }^{4}$ Department of Biomedical Sciences, University of Nevada, Las Vegas -

School of Dental Medicine, Las Vegas, Nevada, USA

Full list of author information is available at the end of the article
}

malignancy process of nearly all cervical cancers, HPV infection is now known to modulate epithelial transformation in breast, lung, penile, anal, and also oral tissues [10-20].

The primary risk factors for oral carcinogenesis are tobacco and alcohol use, although new lines of evidence now suggest HPV may also be an independent risk factor [17-23]. The higher prevalence of high-risk HPV strains in pre-cancerous and cancerous oropharyngeal tumors suggests that HPV may preferentially infect developing or established cancers, thereby modulating carcinogenic progression and ultimately influencing health outcomes [24-26]. In fact, some evidence has suggested that high-risk HPV infection may be associated 
with improved response to treatment and higher survival rates [27-29], while conflicting reports have demonstrated significantly decreased patient survival [30-32] or have observed no discernable and statistically significant effects [33].

Despite the conflicting nature of these results, it is clear that HPV may be involved in modulating tumor responsiveness and carcinogenic progression, therefore many of these studies have provided valuable epidemiological information regarding which high-risk HPV strains are most often implicated in these cases [34-36]. These studies have revealed HPV16, and HPV18 to a lesser extent, accounted for the overwhelming majority (71-94.7\%) of high-risk oral HPV detected [17,18,2123,34-36]. Moreover, new evidence now suggests that these specific high-risk HPV strains (HPV16 and HPV18), may initiate oral carcinogenesis among the smaller fraction of oral cancer patients who do not consume alcohol or use tobacco $[37,38]$.

Based upon the findings of oral HPV in non-tobacco and non-alcohol associated oral cancers, other recent efforts have focused more specifically to evaluate oral HPV prevalence and transmission within healthy populations, which also confirmed that HPV16 and HPV18 were the most commonly detected oral high-risk HPV strains [39-41] among healthy adults.

To this end, a recent pilot study evaluating oral HPV among healthy adults was performed in Nevada [42], a state recently documented with rising rates of oropharyngeal cancers, in stark contrast to the declining rates observed in neighboring states and the US more generally $[43,44]$. This study revealed the presence of highrisk strain HPV16, but not HPV18, among females and minorities, the only population subgroups demonstrated to have rising orpharyngeal cancer rates - despite the overall declining rates observed within the general population [45-47]. This study utilized a saliva-based screening procedure, part of a growing trend towards less invasive methodologies, such as oral lavage- and salivabased screenings, to analyze oral HPV status among healthy adult patients [48-51].

Although prevalence rates ranged widely, these studies have suggested that oral HPV infection may be increasing, not only among adults, but more specifically among younger adults, teenagers, and children [52-54].To this end, some studies have examined oral HPV in children or adolescents, although many of these focused primarily on children with underlying medical conditions, such as co-infection with human immunodeficiency virus (HIV) [55-57]. Most other research, however, has focused more specifically on elucidating the role of vertical HPV transmission in newborns, demonstrating the potential to acquire high-risk HPV during the delivery and birthing process, although these infections typically resolve [58-63].
However, new evidence is emerging that demonstrated high-risk oral HPV infection in normal, healthy children, with the highest rates observed among children under 7 years old (7.9\%-8.7\%), and declining rates observed among healthy adolescents (13-20 years old; 5.1\%-5.2\%) and healthy adults (3.5\%) [64,65]. These observations may suggest that oral HPV infection may occur through close personal contact with family members or through contact with fomites and other vectors at daycare centers, preschool or in primary education settings, with most children immunologically competent to resolve these infections [66]. However, some infections may persist and their contribution to the development of oral cancers and other pathologies remains unclear.

Although a pilot study was recently conducted to evaluate oral HPV status, this involved only healthy adult patients - with no information obtained about oral HPV prevalence among children or teenagers. Based upon the previous evidence demonstrating some level of oral HPV infection in healthy children and adolescents, combined with the lack of data about this population more specifically, the goal of this current study is to provide more detailed information about prevalence of high-risk HPV strains HPV16 and HPV18 in the oral cavity of children and teenagers in Nevada.

\section{Results}

The proportion of female and male specimens from the study sample was not statistically different from the overall proportions within the local community of Clark County, Nevada (Table 1). More specifically, the percentage of females and males in the sample was approximately equal ( $51.7 \%$ and $48.3 \%$, respectively), which was not significantly different than the local area population $(p=0.7051)$. The proportion of minority (non-White) samples was much greater in the study sample (70.3\%) than in the local population (39.1\%), which was statistically significant $(p<0.0001)$. Although data from the local population were unavailable for age-specific comparisons, the study sample was comprised more from younger children (ages 2-11: 59.3\%) than from adolescents and teenagers (12-17: 40.7\%).

Detailed analysis of saliva samples revealed some variability between cell counts, DNA concentration and DNA purity between samples (Figure 1). Cell counts varied between a $0.8-2.3 \times 10^{6} \mathrm{cell} / \mathrm{mL}$, which were further categorized into low $\left(0.8-1.4 \times 10^{6}\right)$ and high $\left(1.6-2.3 \times 10^{6}\right)$ cell counts. DNA was successfully isolated from all saliva samples, with the average DNA concentration for samples observed at $842.7 \mathrm{ng} / \mu \mathrm{L}$. Samples from each cohort (CCSD, UNLV) with cell counts in the low category were found to have lower average concentrations of DNA than samples from the same cohort with cell counts in the high category. Absorbance measurements and A260/A280 ratio 
Table 1 Demographic analysis of study participants

\begin{tabular}{|c|c|c|c|c|c|}
\hline & $\operatorname{CCSD}(n=48)$ & UNLV-SDM $(n=70)$ & Total sample $(n=118)$ & Clark County population & Statistical analysis \\
\hline \multicolumn{6}{|l|}{ Gender } \\
\hline Female & $n=30(62.5 \%)$ & $\mathrm{n}=31(44.3 \%)$ & $\mathrm{n}=61(51.7 \%)$ & $n=969,781(49.7 \%)$ & $x^{2}=0.17849$ d.f. $=1$ \\
\hline Male & $\mathrm{n}=18(37.5 \%)$ & $\mathrm{n}=39(55.7 \%)$ & $\mathrm{n}=57(48.3 \%)$ & $\mathrm{n}=981,488(50.3 \%)$ & $p=0.7051$ \\
\hline \multicolumn{6}{|l|}{ Race } \\
\hline White & $n=12(25 \%)$ & $\mathrm{n}=23(32.9 \%)$ & $\mathrm{n}=35(29.7 \%)$ & $\mathrm{n}=1,188,323(60.9 \%)$ & $x^{2}=28.3634$ d.f. $=1$ \\
\hline Non-White & $n=36(75 \%)$ & $n=47(67.1 \%)$ & $\mathrm{n}=83(70.3 \%)$ & $n=762,946(39.1 \%)$ & $p<0.0001$ \\
\hline \multicolumn{6}{|l|}{ Age } \\
\hline $2-11$ & $n=0(0 \%)$ & $n=70(100 \%)$ & $n=70(59.3 \%)$ & N/A & \\
\hline $12-17$ & $n=48(100 \%)$ & $\mathrm{n}=0(0 \%)$ & $n=48(40.7 \%)$ & N/A & \\
\hline
\end{tabular}

analysis confirmed the purity of DNA isolates, which was approximately equal between cohorts, as well as between samples in the low- and high-cell count categories.

Samples of extracted DNA were subsequently screened for the presence of HPV16 and HPV18 using PCR (Figure 2). This screening yielded three HPV-positive samples $(n=3 / 118)$, representing $2.5 \%$ of the total screened. Two of these samples (S5, S38) harbored HPV16 DNA and one was found to harbor HPV18 DNA

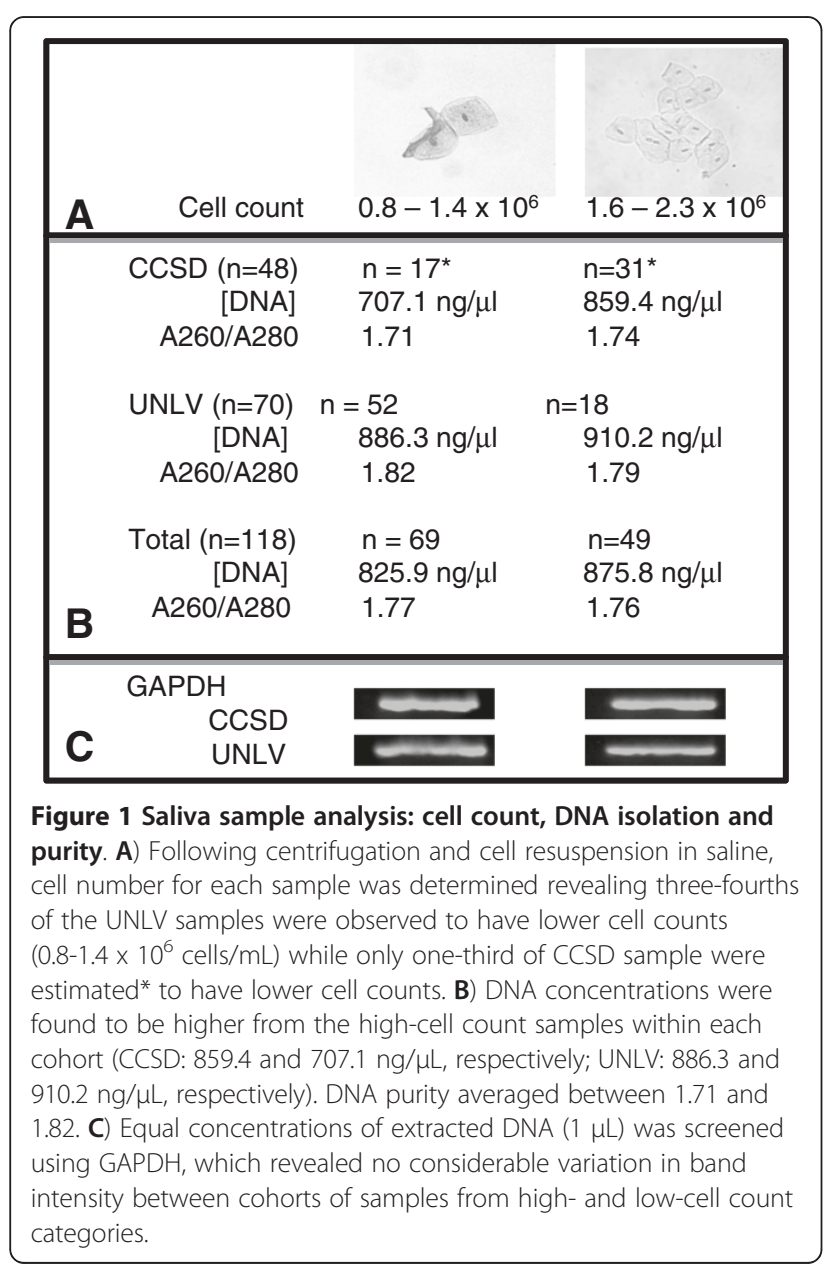

(S7). Processing of DNA samples using qPCR provided quantitative assessments, as well as measurements of sensitivity and specificity. Analysis of copy number per genome for the housekeeping gene ( $\beta$-actin) for the HPV-positive (range: 25 - 40 copies/genome) and HPVnegative samples (4 - 93 copies/genome) revealed values that were well above the cutoff value ( $>0.1$ copies/genome). Results of qPCR analysis revealed copy numbers of HPV-positive samples (range: 150 - 880 copies/genome) that were significantly higher than HPV-negative samples (range: $0.00148-0.0000016$ copies/genome), which could be distinguished using the cutoff value (> 0.001 copies/genome). These analyses revealed no false positives or false negatives, demonstrating sufficient sensitivity and specificity to ascertain the proportion of true HPV-positive samples $(3 / 118$ or $2.5 \%$; $3 / 3$ or $100 \%)$ and true HPV-negative samples $(115 / 118$ or $97.5 \% ; 115 / 115$ or $100 \%)$.

Although the relatively small proportion of HPVpositive samples does not allow for more broad inferences, a descriptive analysis of the demographic information regarding these samples revealed that all three were derived from males $(n=3 / 57$ or $5.3 \%)$ and none were derived from females. The two HPV16-positive samples were collected from White participants aged 14 ( $n=2 / 35$ or $5.7 \%$ ), while the HPV18-positive sample was collected from a non-White participant aged 15 ( $\mathrm{n}=1 / 83$ or $1.2 \%$ ). All three HPV-positive samples were from the CCSD (teenage) cohort ( $n=3 / 48$ or $6.25 \%$ ), while none were observed in the UNLV-SDM (pediatric) cohort $(\mathrm{n}=70)$.

\section{Discussion}

The main goal of this study was to screen normal healthy children and teenagers in Nevada for the presence of high-risk oral HPV. This retrospective analysis used existing saliva samples, collected from pediatric dental patients and local school district teenagers, to obtain novel data from this previously untested juvenile population thereby complementing the ever-growing 


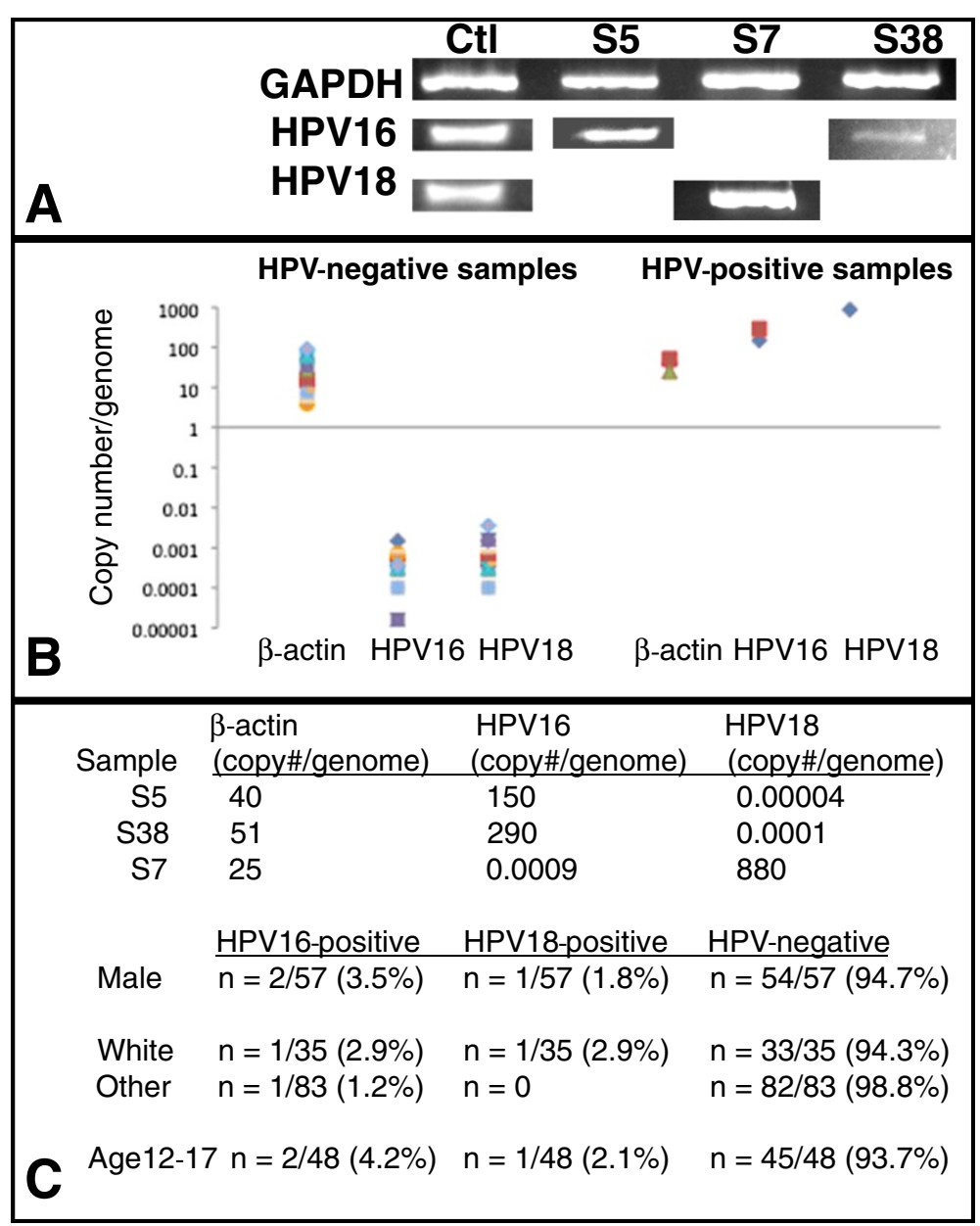

Figure 2 Saliva sample screening: analysis of qPCR HPV results. A) Three samples were found to harbor HPV DNA: HPV16-positive samples (S5, S38); One sample was HPV-positive (S7). B) GPCR analysis revealed HPV-positive samples had values well above the established cutoff value (>0.001 copies/genome). C) All three HPV-positive samples were male, representing $2.5 \%$ of the total $(n=118)$. Two of the three HPV-positive samples were from White participants. All three HPV-positive samples were from the CCSD cohort (ages: 12-17); Both HPV16-positive samples were obtained from 14-year old participants, while the HPV18-positive sample was obtained from a 15-year old.

body of evidence regarding oral HPV prevalence in children. Most importantly, these data have suggested an oral prevalence of high-risk HPV stains of approximately $2.5 \%$.

Recent studies of healthy adults have found similar prevalence rates, ranging between 3.1 and 5\% [40,41]. In fact, the recent pilot study of healthy adults in Nevada reported oral HPV in $2.6 \%$ of 151 cancer-free patients [42]. The results of the current study were markedly different, however, because two of the three HPV-positive samples were obtained from Whites and all were from males - whereas the prior study of adults found oral HPV among females and minorities only. Other evidence has suggested that although samples from females and males had similar rates of oral HPV (56 and 44\%, respectively), the HPV-negative samples from that study were overwhelmingly female $(82 \%)$ - providing some evidence of a possible male, gender-specific phenomenon similar to the current study results [67]. Although there are many possible explanations, such as the transient nature of the local population, many other factors such as stress, diet, income, poverty, socioeconomic status, and oral HPV exposure may affect different racial groups and both genders in similar ways.

This study represents a significant turning point in public health efforts to elucidate oral HPV detection in a geographic area known for higher than average (and previously increasing) rates of oropharyngeal cancers $[43,44]$. However, this study had several limitations that must be acknowledged. First, the retrospective nature of this study limited the inferences that could be made, unlike other recent prospective studies of oral HPV in children and adolescents [64-68]. In addition, no detailed behavioral or socioeconomic data were available, such as parental income or smoking behaviors, due to the nature of this retrospective pilot study. It is hoped that future investigations involving oral HPV will provide additional 
insights with more detailed behavioral information, as well as data regarding housing, education, income and other socioeconomic indicators [67-71].

\section{Conclusions}

This project successfully screened saliva samples for high-risk HPV, confirming both HPV16 and HPV18 strains were present in a small subset. Although previous work has focused on oral HPV transmission from mother to newborn during birth and while nursing $[58-63,68]$, there is growing evidence to suggest that following the perinatal period, oral HPV transmission through close personal contact, such as shared eating utensils, toys, kissing and bathing may account for oral HPV transmission (primarily HPV16) in children and adolescents [72-75]. This study, therefore, provides critical information of significant value to other dental, medical, oral and public health professionals who seek to further an understanding of high-risk HPV prevalence among children as part of a broader understanding of oral health and disease risk in pediatric populations.

\section{Methods}

\section{Sample size}

Given the known prevalence of high-risk oral HPV in the previous study that screened healthy adults within this geographic area, the appropriate sample size was calculated using the following formula: $\mathrm{n}=Z^{2} P(1-P)$ $/ d^{2}$, where $\mathrm{n}=$ sample size, $Z=Z$ statistic for a level of confidence, $P=$ expected prevalence, and $d=$ precision $[76,77]$. Using the $95 \%$ level of confidence, the $Z$ value was determined to be 1.96; Using the previous proportion/prevalence of high-risk HPV of $2.6 \%$, the $P$ value was set as $P=0.026$; The value for $d$ should be calculated at $0.5(P)$, resulting in a value for $d=0.013$. Using these inputs, the minimum sample size for this study was calculated to be $\mathrm{n}=75$.

\section{Human subjects}

The protocol for this study titled "Retrospective Evaluation of Microbial Presence in Existing Saliva Repository: A PCR-Based Molecular Survey of Oral Microbial Populations from Existing Saliva Samples" was filed, amended, and approved by the UNLV Office of Research Integrity - Human Subjects (OPRS\#1104-3801M) on May 10, 2011. The existing saliva samples were collected during two previous studies within the UNLV School of Dental Medicine (SDM) during 2009-2010. Saliva samples collected from a prior study of teenagers (14-15 years old) were derived from a convenience sample of selected schools within the Clark County, Nevada School District (CCSD; $n=48$ ); originally obtained for the purpose of surveying levels of oral cariogenic bacteria. Saliva samples collected from young children (2-11 years old) were obtained from a convenience sample within the UNLV-SDM pediatric dental clinic $(n=70)$; originally obtained for the purpose of screening for heavy metal (lead or $\mathrm{Pb}$ ) burden. In brief, for the original saliva sample collections at CCSD and UNLV-SDM, parents and subjects were recruited onsite. Inclusion criteria: Informed Consent/Parent Permission was required and conducted onsite, as well as an Assent to Participate in Research for all children over the age of seven who were capable of reading. Exclusion criteria: subjects younger than seven years of age, subjects that declined to participate, and subjects with parents who declined to participate. Each sample was assigned a unique, randomly-generated number to prevent research bias, with the only demographic information regarding the saliva specimens: gender, age, and ethnicity of the original study participant. This current project was a retrospective analysis of these two collections of saliva samples; the total combined sample size for this study was $\mathrm{n}=118$.

\section{Saliva collection protocol}

In brief, subjects who agreed to participate were given a small, sterile saliva collection container, $50 \mathrm{~mL}$ sterile polypropylene tube (Fisher Scientific: Fair Lawn, New Jersey, USA). Participants were then asked to chew on a small piece of paraffin wax for one minute and then to expectorate, in accordance with the previous pilot study protocol [42]; sample volumes varied from approximately $50 \mu \mathrm{L}$ to $2.5 \mu \mathrm{L}$. Samples were stored on ice until transport to a biomedical laboratory for analysis. Each saliva sample was assigned a unique, randomlygenerated number to prevent research bias. Demographic information regarding the sample was concurrently collected, which consisted of age, gender, and ethnicity only.

\section{Cell counting and DNA isolation}

All samples were centrifuged for 10 minutes at 2,100 g (RCF) and the cell pellet washed with $1 \mathrm{X}$ phosphatebuffered saline (PBS) (HyClone: Logan, Utah, USA) and resuspended in $5 \mathrm{~mL}$ of $1 \mathrm{X}$ PBS. Cell number was determined using Trypan Blue (Fisher Scientific: Fair Lawn, New Jersey, USA) using a Zeiss Axiovert 40 inverted microscope (Carl Ziess, Inc: Thornwood, New York, USA) and a hemacytometer (Fisher Scientific: Fair Lawn, New Jersey, USA). To determine if any samples harbored the HPV virus, DNA was isolated from the saliva sample using a minimum of $3.5 \times 10^{5}$ cells using the GenomicPrep DNA isolation kit (Amersham Biosciences: Buckinghamshire, United Kingdom), using the procedure recommended by the manufacturer as previously described $[12,42,78,79]$. DNA purity was calculated using ratio measurements of absorbance at 260 and $280 \mathrm{~nm}$ (A260/A280 ratio between 1.7 and 2.0). 


\section{Polymerase chain reaction (PCR)}

DNA from each sample was then used to perform PCR with the Fisher exACTGene complete PCR kit (Fisher Scientific: Fair Lawn, New Jersey, USA) and a Mastercycler gradient thermocycler (Eppendorf: Hamburg, Germany) using the following primers for HPV16 [12,78], HPV18 [12,78,79], and glyceraldehyde- 3- phosphate dehydrogenase (GAPDH) [80] (SeqWright: Houston, Texas, USA):

HPV16 forward primer, ATGTTTCAGGACCCACA GGA;

HPV16 reverse primer, CCTCACGTCGCAGTAAC TGT.

HPV18 forward primer, ATGGCGCGCTTTGAGGA TCC;

HPV18 reverse primer, GCATGCGGTATACTGTC TCT;

GAPDH forward primer, ATCTTCCAGGAGCGAGA TCC;

GAPDH reverse primer, ACCACTGACACGTTGGC AGT;

One $\mu \mathrm{g}$ of template DNA was used for each reaction. The initial denaturation step ran for three minutes at $94^{\circ} \mathrm{C}$. A total of 30 amplification cycles were run, consisting of 30 second denaturation at $94^{\circ} \mathrm{C}, 60$ seconds of annealing at $58^{\circ} \mathrm{C}$, and 30 seconds of extension at $72^{\circ} \mathrm{C}$. Final extension was run for five minutes at $72^{\circ} \mathrm{C}$. The PCR reaction products were separated by gel electrophoresis using Reliant 4\% NuSieve ${ }^{\circledR}$ 3:1 Plus Agarose gels (Lonza: Rockland, Maine, USA). Bands were visualized by UV illumination of ethidium-bromide-stained gels and captured using a Kodak Gel Logic 100 Imaging System and 1D Image Analysis Software (Eastman Kodak: Rochester, New York, USA).

\section{Quantitative PCR (qPCR)}

DNA samples were then processed using qPCR to provide more specific and sensitive quantification. Primers and probes were designed using Roche Universal Probe library (UPL) assay design software to amplify the region overlapping E6 and E7 gene sequence of HPV16 (GenBank accession no. K02718) and the human $\beta$-actin housekeeping gene (GenBank accession no. M10277). These primers were purchased from Sigma-Aldrich (St. Louis, Missouri, USA) and probes from Roche Applied Science (Indianapolis, Indiana, USA).

HPV16 E6/E7 forward primer 5/-CAACTGATCTC TACTGTTATGAGCAA-3/, HPV16 E6/E7 reverse primer 5/-CCAGCTGGACCATCTATTTCA-3/, HPV16 E6/E7 hydrolysis "Taqman" probe 5/-(fam)-AGGAGGAG-(dark quencher dye)-3/ (UPL probe \#63) was used to amplify the 73 base pair (bp) region between the 535 nucelotide (nt) position and 607 nt position. HPV18 E7 forward primer 5/-GACTCAGAGGAAGGAAAACGATGAAA, HPV18
E7 reverse primer 5/-GTGACGTTGTGGTTCGGCT; HPV18 E7 probe 5/-TGGAGTTAATCATCAACATT TACCA was used to amplify the 25 bp region between the 715 and 739 nt position. Human $\beta$-actin forward primer 5/-GTGGGGTCCTGTGGTGTG-3/, human $\beta$-actin 5/-GAAGGGGACAGGCAGTGA-3/, human $\beta$-actin hydrolysis "Taqman" probe 5/-(fam)-GGGAGCTG-(dark quencher dye)-3/ (UPL probe \#24) amplified the $61 \mathrm{bp}$ region between $2642 \mathrm{nt}$ position and $2702 \mathrm{nt}$ position.

The real-time reaction mixture was prepared in a LightCycler $^{\circledR} 480$ multiwell Plate 96 containing 1x LightCycler $^{\circledR} 480$ Probes Master (Roche Applied Sciences: Indianapolis, Indiana, USA), $1 \mu \mathrm{M}$ of each respective primer set (forward and reverse), $0.2 \mu \mathrm{M}$ of respective probe, and $2 \mu \mathrm{l}$ of DNA template; in a $20 \mu \mathrm{l}$ final reaction volume. The probes master mix contained reaction buffer, dNTP mix (including dUTP in place of dTTP), $3.2 \mathrm{mM} \mathrm{MgCl}_{2}$, and Taq DNA polymerase. The realtime PCR assay was performed on a LightCycler 480 system (Roche Applied Sciences: Indianapolis, Indiana, USA) with the following cycle parameters: preincubation for initial enzyme activation at $95^{\circ} \mathrm{C}$ for 10 minutes, followed by 45 cycles of $95^{\circ} \mathrm{C}$ for 10 seconds (ramp rate $4.4^{\circ} \mathrm{C} /$ second), $60^{\circ} \mathrm{C}$ for 30 seconds (ramp rate $2.2^{\circ} \mathrm{C} /$ second) and $72^{\circ} \mathrm{C}$ for 1 second (ramp rate $4.4^{\circ} \mathrm{C} /$ second). Following amplification phase, a cooling step was performed at $40^{\circ} \mathrm{C}$ for 30 seconds (ramp rate of $2.2^{\circ} \mathrm{C} /$ second). Acquisition of the fluorescence signal was performed using Mono Hydrolysis Probe setting (465-510 nm) following the $72^{\circ} \mathrm{C}$ extension phase of each cycle. All samples were carried out in triplicate.

The CaSki (American Type Culture Collection; Manassas, Virginia, USA) cervical adenocarcinoma cell line was used to develop standard curves for both the HPV16 (600 copies/genome) and GAPDH (2 copies/genome) genes. The GH354 (American Type Culture Collection; Manassas, Virginia, USA) cervical adenocarcinoma cell line was used to develop the standard curves for HPV18 (200 copies/genome). DNA extracted from CaSki and GH354 cells were serially diluted tenfold starting at $50 \mathrm{ng}$ to $0.0005 \mathrm{ng}$ [81] Quantification was achieved using Cycle Threshold $\left(C_{\mathrm{T}}\right)$ measured with the second derivative maximum method (LightCycler 480 Software version 1.5.0.39; Roche Applied Sciences: Indianapolis, Indiana, USA). Saliva samples > 0.001 copy/genome were considered HPV positive. Specificity analysis was performed on qPCR assay against HPV18 and found to be $100 \%$ specific (data not shown).

\section{Statistical evaluation}

Sensitivity and specificity were calculated as the proportion of true positives and true negatives (cutoff value $>0.001$ copies/genome), respectively. Following the acquisition of saliva samples and HPV screening results, 
demographic information from the samples were compared with the overall demographic profile of the local population using a chi-square $\left(\mathrm{X}^{2}\right)$ test, to determine if any characteristic (gender, race, age) was different than expected among the subjects evaluated in this study $(\mathrm{n}=118)$. A probability level of alpha $(\alpha)=0.05$ was used to determine statistical significance.

\section{Abbreviations}

HPV: Human papillomavirus; DNA: Deoxyribonucleic acid; US: United States; PCR: Polymerase chain reaction; OPRS: Office for the Protection of Human Research Subjects; CCSD: Clark County Nevada - School District; UNLVSDM: University of Nevada Las Vegas - School of Dental Medicine: RCF: Relative centrifugal force; PBS: Phosphate-buffered saline; GAPDH: Glyceraldehyde-3- phosphate dehydrogenase; qPCR: Quantitative polymerase chain reaction; bp: Base pair; nt: Nucleotide; dNTP: Deoxyribonucleotide triphosphate; dUTP: 2-Deoxyuridine triphosphate; dTTP: Deoxythymidine triphosphate.

\section{Competing interests}

The authors declare they have no competing interests.

\section{Authors' contributions}

KK and CF conceived, monitored, and coordinated the experimental design. $\mathrm{KH}, \mathrm{EE}, \mathrm{JA}$ and $\mathrm{AH}$ were responsible for recruiting subjects, informed consent, collecting samples, and some biomedical analysis. CF, EE, JA, and AH carried out the DNA extractions, $\mathrm{PCR}$, and $\mathrm{gPCR}$ analysis. $\mathrm{KK}$ and $\mathrm{KH}$ were responsible for the data analysis, as well as the writing and editing of this manuscript. All authors read and approved the final manuscript.

\section{Acknowledgements}

The authors would like to thank the UNLV School of Community Health Sciences and UNLV-SDM Department of Biomedical Sciences, Office for Research, and Advanced Education Program in Pediatric Dentistry for providing the supplies and reagents for this initial pilot study.

\section{Author details}

'Department of Advanced Education in Pediatric Dentistry, University of Nevada, Las Vegas - School of Dental Medicine, Las Vegas, Nevada, USA. ${ }^{2}$ Department of Environmental and Occupational Health, University of Nevada, Las Vegas - School of Community Health Sciences, Las Vegas, Nevada, USA. ${ }^{3}$ University of Nevada, Las Vegas - School of Life Sciences, Las Vegas, Nevada, USA. ${ }^{4}$ Department of Biomedical Sciences, University of Nevada, Las Vegas - School of Dental Medicine, Las Vegas, Nevada, USA.

Received: 8 February 2012 Accepted: 18 October 2012

Published: 22 October 2012

\section{References}

1. Zhou W, Tyring SK, Brysk M, Chan T: Immortalization of differentiated human keratinocytes by human papillomavirus (HPV) 16 DNA. J Dermat Sci. 1996, 13:140-152.

2. zur Hausen H: Papillomaviruses in human cancers. Proc Assoc Am Physicians 1999, 111(6):581-587. Review.

3. zur Hausen H: Papillomaviruses and cancer: from basic studies to clinical application. Nat Rev Cancer 2002, 2(5):342-350.

4. McCance DJ: Human papillomaviruses and cancer. Biochim Biophys Acta 1986, 823:195-205.

5. Walboomers JMM, Jacobs MV, Manos MM, Bosch FX, Kummer JA, Shah KV, Snijders PJF, Peto J, Meijer CJLM, Munoz N: Human papillomavirus is a necessary cause of invasive cervical cancer worldwide. J Pathol 1999, 189:12-19.

6. Clifford GM, Smith JS, Plummer M, Munoz N, Franceschi S: Human papillomavirus types in invasive cervical cancer worldwide: a meta-analysis. Br J Cancer 2003, 88:63-73.

7. Kalantari M, Blennow E, Hagmar B, Johansson B: Physical state of HPV16 and chromosomal mapping of the integrated form in cervical carcinomas. Diagn Mol Pathol 2001, 10(1):46-54.
8. Biron VL, Côté DW, Seikaly H: Oropharyngeal squamous cell carcinoma and human papillomavirus-associated cancers in women: epidemiologic evaluation of association. J Otolaryngol Head Neck Surg 2011, 40(Suppl 1): S65-9.

9. Tornesello ML, Losito S, Benincasa G, Fulciniti F, Botti G, Greggi S, Buonaguro L, Buonaguro FM: Human papillomavirus (HPV) genotypes and HPV16 variants and risk of adenocarcinoma and squamous cell carcinoma of the cervix. Gynecol Oncol 2011, 121(1):32-42.

10. Kan C-Y, lacopetta BJ, Lawson JS, Whitaker NF: Identification of human papillomavirus DNA sequences in human breast cancer. Br J Cancer 2005, 93:946-948.

11. Amarante MK, Watanabe MA: The possible involvement of virus in breast cancer. J Cancer Res Clin Oncol 2009, 135(3):329-337. Epub 2008 Nov 14.

12. Kingsley K, Zuckerman J, Davis M, Matteucci M, Knavel A, Rinehart J, Tran V, Woyciehowsky D, Jenkins P, Yu R, Nguyen DH, O'Malley S: Induction of Differential Growth in vitro by High-risk Human Papillomavirus in Human Breast Cancer Cell Lines is Associated with Caspase Dysregulation. J Cancer Sci Ther 2009, 1(2):62-71.

13. Rezazadeh A, Laber DA, Ghim SJ, Jenson AB, Kloecker G: The role of human papilloma virus in lung cancer: a review of the evidence. Am J Med Sci 2009, 338(1):64-7.

14. Miralles-Guri C, Bruni L, Cubilla AL, Castellsagué X, Bosch FX, de Sanjosé S: Human papillomavirus prevalence and type distribution in penile carcinoma. J Clin Pathol 2009, 62(10):870-878. Epub 2009 Aug 25.

15. Pow-Sang MR, Ferreira U, Pow-Sang JM, Nardi AC, Destefano V: Epidemiology and natural history of penile cancer. Urology 2010, 76 (2 Suppl 1):S2-6.

16. Williams GR, Talbot IC: Anal carcinoma-a histological review. Histopathology 1994, 25(6):507-16.

17. Shukla S, Bharti AC, Mahata S, Hussain S, Kumar R, Hedau S, Das BC: Infection of human papillomaviruses in cancers of different human organ sites. Indian J Med Res 2009, 130(3):222-33.

18. Gillison ML, Koch WM, Capone RB, Spafford M, Westra WH, Wu L, Zahurak ML, Daniel RW, Viglione M, Symer DE, Shah KV, Sidransky D: Evidence for a causal association between human papillomavirus and a subset of head and neck cancers. J Natl Cancer Inst 2000, 92:675-677.

19. Miller CS, Johnstone BM: Human papillomavirus as a risk factor for oral squamous cell carcinoma: a meta-analysis, 1982-1997. Oral Surg Oral Med Oral Pathol 2001, 91:622-635.

20. van Houten VM, Snijders PJ, van den Brekel MW, Kummer JA, Meijer CJ, van Leeuwen B, Denkers F, Smeele LE, Snow GB, Brakenhoff RH: Biological evidence that human papillomaviruses are etiologically involved in a subgroup of head and neck squamous cell carcinomas. Int J Cancer 2001, 93:232-235

21. Herrero R, Castellsague X, Pawlita M, Lissowska J, Kee F, Balaram P, Rajkumar T, Sridhar H, Rose B, Pintos J, Fernandez L, Idris A, Jose Sanchez M, Nieto A, Talamini R, Tavani A, Bosch FX, Reidel U, Snijders PJF, Meijer CJLM, Viscidi R, Munoz N, Franceschi S: Human papillomavirus and oral cancer: The International Agency for Research on Cancer multicenter study. J Natl Cancer / 2003, 95:1772-1783.

22. Kreimer AR, Clifford GM, Boyle P, Franceschi S: Human papillomavirus types in head and neck squamous cell carcinomas worldwide: a systematic review. Cancer Epidemiol Biomarkers Prev 2005, 14:467-475.

23. Syrjanen S: Human papillomavirus (HPV) in head and neck cancer. J Clin Virol 2005, 32:559-66.

24. Schwartz SR, Yueh B, McDougall JK, Daling JR, Schwartz SM: Human papillomavirus infection and survival in oral squamous cell cancer: a population-based study. Otolaryngol Head Neck Surg 2001, 125(1):1-9.

25. Badaracco G, Rizzo C, Mafera B, Pichi B, Giannarelli D, Rahimi SS, Vigili MG, Venuti A: Molecular analyses and prognostic relevance of HPV in head and neck tumours. Oncol Rep 2007, 17(4):931-9.

26. Mehta V, Yu GP, Schantz SP: Population-based analysis of oral and oropharyngeal carcinoma: Changing trends of histopathologic differentiation, survival and patient demographics. Laryngoscope 2010 120(11):2203-12.

27. Cojocariu OM, Huguet $F$, Lefevre $M$, Périé $\mathrm{S}$ : Prognosis and predictive factors in head-and-neck cancers. Bull Cancer 2009, 96(4):369-78.

28. Sharma A, Méndez E, Yueh B, Lohavanichbutr P, Houck J, Doody DR, Futran ND, Upton MP, Schwartz SM, Chen C: Human papillomavirus-positive oral cavity and oropharyngeal cancer patients do not have better quality-oflife trajectories. Otolaryngol Head Neck Surg 2012, 146(5):739-45. 
29. Smith EM, Rubenstein LM, Haugen TH, Pawlita M, Turek LP: Complex etiology underlies risk and survival in head and neck cancer human papillomavirus, tobacco, and alcohol: a case for multifactor disease. J Oncol. 2012, 2012:571862

30. Duray A, Descamps G, Decaestecker C, Remmelink M, Sirtaine N, Lechien J, Ernoux-Neufcoeur P, Bletard N, Somja J, Depuydt CE, Delvenne P, Saussez S: Human papillomavirus DNA strongly correlates with a poorer prognosis in oral cavity carcinoma. Laryngoscope 2012, 122(7):1558-65.

31. Huang SF, Li HF, Liao CT, Wang HM, Chen IH, Chang JC, Chen YJ, Cheng AJ: Association of HPV infections with second primary tumors in earlystaged oral cavity cancer. Oral Dis 2012, 18(8):809-15.

32. Lee LA, Huang CG, Liao CT, Lee LY, Hsueh C, Chen TC, Lin CY, Fan KH, Wang HM, Huang SF, Chen IH, Kang CJ, Ng SH, Yang SL, Tsao KC, Chang YL, Yen TC: Human papillomavirus-16 infection in advanced oral cavity cancer patients is related to an increased risk of distant metastases and poor survival. PLoS One 2012, 7(7):e40767.

33. Lohavanichbutr $P$, Houck J, Doody DR, Wang P, Mendez E, Futran N, Upton MP, Holsinger FC, Schwartz SM, Chen C: Gene Expression in Uninvolved Oral Mucosa of OSCC Patients Facilitates Identification of Markers Predictive of OSCC Outcomes. PLoS One 2012, 7(9):e46575.

34. Mao EJ: Prevalence of human papillomavirus 16 and nucleolar organizer region counts in oral exfoliated cells from normal and malignant epithelia. Oral Surg Oral Med Oral Pathol Oral Radiol Endod 1995, 80(3):320-9.

35. Bouda M, Gorgoulis VG, Kastrinakis NG, Giannoudis A, Tsoli E, Danassi-Afentaki D, Foukas P, Kyroudi A, Laskaris G, Herrington CS, Kittas C: "High risk" HPV types are frequently detected in potentially malignant and malignant oral lesions, but not in normal oral mucosa. Mod Pathol 2000, 13(6):644-53.

36. D'Souza G, Kreimer AR, Viscidi R, Pawlita M, Fakhry C, Koch WM, Westra WH, Gillison ML: Case-control study of human papillomavirus and oropharyngeal cancer. N Engl J Med 2007, 356(19):1944-56.

37. Zhao D, Xu QG, Chen XM, Fan MW: Human papillomavirus as an independent predictor in oral squamous cell cancer. Int J Oral Sci 2009, 1(3):119-25.

38. Andrews E, Seaman WT, Webster-Cyriaque J: Oropharyngeal carcinoma in non-smokers and non-drinkers: a role for HPV. Oral Oncol 2009, 45(6):486491. Epub 2008 Nov 21.

39. do Sacramento PR, Babeto E, Colombo J, Cabral Ruback MJ, Bonilha JL, Fernandes AM, Pereira Sobrinho JS, de Souza FP, Villa LL, Rahal P: The prevalence of human papillomavirus in the oropharynx in healthy individuals in a Brazilian population. J Med Virol 2006, 78(5):614-618.

40. Kreimer AR, Villa A, Nyitray A, Abrahamsen ME, Papenfuss MR, Smith D, Hildesheim A, Villa LL, Lazcano-Ponce E, Giuliano AR: The epidemiology of oral HPV infection among a multinational sample of healthy men. Cancer Epidemiol Biomarkers Prev 2011, 20(1):172-182.

41. Kreimer AR, Bhatia RK, Messeguer AL, González P, Herrero R, Giuliano AR: Oral human papillomavirus in healthy individuals: a systematic review of the literature. Sex Transm Dis 2010, 37(6):386-91.

42. Turner DO, Williams-Cocks SJ, Bullen R, Catmull J, Falk J, Martin D, Mauer J, Barber AE, Wang RC, Gerstenberger SL, Kingsley K: High-risk human papillomavirus (HPV) screening and detection in healthy patient saliva samples: a pilot study. BMC Oral Health 2011, 11:28.

43. Kingsley K, O'Malley S, Chino M: Analysis of oral cancer epidemiology in the US reveals state-specific trends: implications for oral cancer prevention. BMC Public Health 2008, 8(1):87.

44. Bunnell A, Pettit N, Reddout N, Sharma K, O'Malley S, Chino M, Kingsley K: Analysis of primary risk factors for oral cancer from select US states with increasing rates. Tob Induc Dis. 2010, 8:5.

45. Swango PA: Cancers of the oral cavity and pharynx in the United States: an epidemiologic overview. J Public Health Dent 1996, 56:309-318.

46. Shiboski $\mathrm{CH}$, Shiboski SC, Silverman S Jr: Trends in oral cancer rates in the United States, 1973-1996. Community Dent Oral Epidemiol 2000, 28:249-256.

47. Edwards BK, Howe HL, Ries LA, Thun MJ, Rosenberg HM, Yanick R, Wingo $P A$, Jemal A, Feigal EG: Annual report to the nation on the status of cancer, 1973-1999, featuring implications of age and aging on U.S. cancer burden. Cancer 2002, 94:2766-2792.

48. Gonçalves AK, Giraldo P, Barros-Mazon S, Gondo ML, Amaral RL, Jacyntho C: Secretory immunoglobulin A in saliva of women with oral and genital HPV infection. Eur J Obstet Gynecol Reprod Biol 2006, 124(2):227-231. Epub 2005 Sep 6

49. SahebJamee M, Boorghani M, Ghaffari SR, AtarbashiMoghadam F, Keyhani A: Human papillomavirus in saliva of patients with oral squamous cell carcinoma. Med Oral Patol Oral Cir Bucal 2009, 14(10):e525-8.
50. Seaman WT, Andrews E, Couch M, Kojic EM, Cu-Uvin S, Palefsky J, Deal AM, Webster-Cyriaque J: Detection and quantitation of HPV in genital and oral tissues and fluids by real time PCR. Virol J 2010, 7:194.

51. Zhao M, Rosenbaum E, Carvalho AL, Koch W, Jiang W, Sidransky D, Califano $\mathrm{J}$ : Feasibility of quantitative PCR-based saliva rinse screening of HPV for head and neck cancer. Int J Cancer 2005, 117(4):605-10.

52. Trottier H, Burchell AN: Epidemiology of mucosal human papillomavirus infection and associated diseases. Public Health Genomics 2009, 12(5-6):291-307. Epub 2009 Aug 11.

53. Chaudhary AK, Singh M, Sundaram S, Mehrotra R: Role of human papillomavirus and its detection in potentially malignant and malignant head and neck lesions: updated review. Head Neck Oncol 2009, 1:22. Review.

54. Chow CW, Tabrizi SN, Tiedemann K, Waters KD: Squamous cell carcinomas in children and young adults: a new wave of a very rare tumor? J Pediatr Surg 2007, 42(12):2035-9.

55. Schiødt M: Less common oral lesions associated with HIV infection: prevalence and classification. Oral Dis 1997, 3(Suppl 1):S208-213. Review.

56. Feller L, Khammissa RA, Wood NH, Malema V, Meyerov R, Lemmer J: Focal epithelial hyperplasia (Heck disease) related to highly active antiretroviral therapy in an HIV-seropositive child. A report of a case, and a review of the literature. SADJ 2010, 65(4):172-175. Review.

57. Pinheiro RS, de França TR, Rocha B, Ferreira DC, Ribeiro CM, Cavalcanti SM, de Souza IP, Leão JC, Castro GF: Human papillomavirus coinfection in the oral cavity of HIV-infected children. J Clin Pathol 2011, 64(12):1083-7.

58. Rombaldi RL, Serafini EP, Mandelli J, Zimmermann E, Losquiavo KP: Perinatal transmission of human papilomavirus DNA. Virol J 2009, 6:83.

59. Saini R, Khim TP, Rahman SA, Ismail M, Tang TH: High-risk human papillomavirus in the oral cavity of women with cervical cancer, and their children. Virol J 2010, 7:131.

60. Smith EM, Parker MA, Rubenstein LM, Haugen TH, Hamsikova E, Turek LP: Evidence for vertical transmission of HPV from mothers to infants. Infect Dis Obstet Gynecol 2010, 2010:326369.

61. Syrjänen S: Current concepts on human papillomavirus infections in children. APMIS 2010, 118(6-7):494-509. Review.

62. Koskimaa HM, Waterboer T, Pawlita M, Grénman S, Syrjänen K, Syrjänen S: Human papillomavirus genotypes present in the oral mucosa of newborns and their concordance with maternal cervical human papillomavirus genotypes. J Pediatr 2012, 160(5):837-43.

63. Martinelli M, Zappa A, Bianchi S, Frati E, Colzani D, Amendola A, Tanzi E: Human papillomavirus (HPV) infection and genotype frequency in the oral mucosa of newborns in Milan, Italy. Clin Microbiol Infect 2012, 18(6): E197-9.

64. Marais DJ, Sampson C, Jeftha A, Dhaya D, Passmore JA, Denny L, Rybicki EP, Van Der Walt E, Stephen LX, Williamson AL: More men than women make mucosal IgA antibodies to Human papillomavirus type 16 (HPV-16) and HPV-18: a study of oral HPV and oral HPV antibodies in a normal healthy population. BMC Infect Dis 2006, 6:95

65. Summersgill KF, Smith EM, Levy BT, Allen JM, Haugen TH, Turek LP: Human papillomavirus in the oral cavities of children and adolescents. Oral Surg Oral Med Oral Pathol Oral Radiol Endod 2001, 91(1):62-9.

66. Rautava J, Syrjänen S: Human papillomavirus infections in the oral mucosa. J Am Dent Assoc 2011, 142(8):905-14.

67. Sinclair KA, Woods CR, Kirse DJ, Sinal SH: Anogenital and respiratory tract human papillomavirus infections among children: age, gender, and potential transmission through sexual abuse. Pediatrics 2005, 116(4):815-25.

68. Castellsagué X, Drudis T, Cañadas MP, Goncé A, Ros R, Pérez JM, Quintana MJ, Muñoz J, Albero G, de Sanjosé S, Bosch FX: Human Papillomavirus (HPV) infection in pregnant women and mother-to-child transmission of genital HPV genotypes: a prospective study in Spain. BMC Infect Dis 2009, 9:74.

69. Smith EM, Ritchie JM, Summersgill KF, Klussmann JP, Lee JH, Wang D, Haugen TH, Turek LP: Age, sexual behavior and human papillomavirus infection in oral cavity and oropharyngeal cancers. Int J Cancer 2004, 108 (5):766-72.

70. Tachezy R, Klozar J, Rubenstein L, Smith E, Saláková M, Smahelová J, Ludvíková V, Rotnáglová E, Kodet R, Hamsíková E: Demographic and risk factors in patients with head and neck tumors. J Med Virol 2009, 81 (5):878-87.

71. D'Souza G, Agrawal Y, Halpern J, Bodison S, Gillison ML: Oral sexual behaviors associated with prevalent oral human papillomavirus infection. J Infect Dis 2009, 199(9):1263-9. 
72. Kim JJ, Goldie SJ: Health and economic implications of HPV vaccination in the United States. N Engl J Med 2008, 359(8):821-32.

73. Pinheiro Rdos S, de França TR, Ferreira Dde C, Ribeiro CM, Leão JC, Castro GF: Human papillomavirus in the oral cavity of children. $J$ Oral Pathol Med 2011, 40(2):121-126.

74. Mant C, Kell B, Rice P, Best JM, Bible JM, Cason J: Buccal exposure to human papillomavirus type 16 is a common yet transitory event of childhood. J Med Virol 2003, 71:593-598.

75. Summersgill KF, Smith EM, Levy BT, Allen JM, Haugen TH, Turek LP: Human papillomavirus in the oral cavities of children and adolescents. Oral Surg Oral Med Oral Pathol Oral Radiol Endod 2001, 91:62-69.

76. Naing L, Winn T, Rusli BN: Practical issues in calculating sample size for prevalence studies. Archives of Orofacial Sciences. 2006, 1:9-14.

77. Daniel WW: Biostatistics: A Foundation for Analysis in the Health Sciences. 7th edition. New York: John Wiley \& Sons; 2006.

78. Kingsley K, Johnson D, O'Malley S: Transfection of oral squamous cell carcinoma with human papillomavirus-16 induces proliferative and morphological changes independent of cellular adhesion in vitro. Cancer Cell Int. 2006, 6:14.

79. Reddout N, Christensen T, Bunnell A, Jensen D, Johnson D, O'Malley S, Kingsley K. High risk HPV types 18 and 16 are potent modulators of oral squamous cell carcinoma phenotypes in vitro. Infect. Agent Cancer 2007, 2(1):21.

80. Wolter F, Turchanowa L, Stein J: Resveratrol-induced modification of polyamine metabolism is accompanied by induction of c-Fos. Carcinogenesis 2003, 24(3):469-74

81. Chuang AY, Chuang TC, Chang S, Zhou S, Begum S, Westra WH, Ha PK, Koch WM, Califano JA: Presence of HPV DNA in convalescent salivary rinses is an adverse prognostic marker in head and neck squamous cell carcinoma. Oral Oncol 2008, 44(10):915-919. Epub 2008 Mar 7.

doi:10.1186/1472-6831-12-43

Cite this article as: Flake et al: Screening and detection of human papillomavirus (HPV) high-risk strains HPV16 and HPV18 in saliva samples from subjects under 18 years old in Nevada: a pilot study. BMC Oral Health 2012 12:43.

\section{Submit your next manuscript to BioMed Central and take full advantage of:}

- Convenient online submission

- Thorough peer review

- No space constraints or color figure charges

- Immediate publication on acceptance

- Inclusion in PubMed, CAS, Scopus and Google Scholar

- Research which is freely available for redistribution 